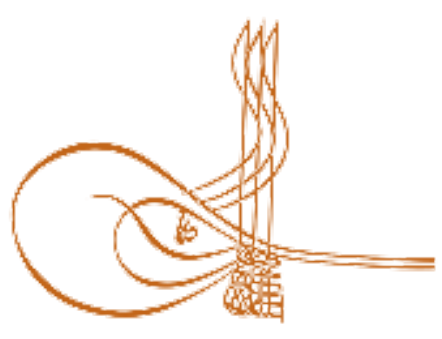

www.turkishstudies.net/education
Turkish Studies - Educational Sciences

eISSN: 2667-5609

Research Article / Araștırma Makalesi

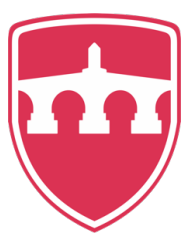

INTERNATIONAL BALKAN

UNIVERSITY

Sponsored by IBU

\title{
Yurt Dışında Türkçe ve Türk Kültürü Dersine Katılan Öğrencilerin Türkçe Okuduğunu Anlama Başarıları
}

\author{
The Achievements of Students Attended to the Turkish and Turkish Culture \\ Course Abroad
}

Bayram Arıc1*

\begin{abstract}
This research was carried out to determine the reading comprehension skill levels of students attending Turkish and Turkish Culture courses abroad. The study group of the research consists of two groups of 30 students (experimental group 30, control group 30), who are studying in the city of Nuremberg in the Federal Republic of Germany and its surroundings, and who attend Turkish and Turkish Culture lessons, mostly of Turkish origin. Working groups were determined by simple random sampling method. Understanding studies were carried out for the experimental group for four months reading twice a week. These studies were not made to the control group students. The same texts were taught to both groups at the beginning and end of the application in the second semester of the 2016-2017 academic year. According to the pretest results made before the research, the average score of the experimental group was 61.80 ; The mean score of the control group was 61.60 , and no significant difference was found among the groups in terms of the mean score. The average scores of the students in the experimental group who attended the classes after the application were 81.00; the average score of the students in the control group was determined to be 62.13 . According to these results, it has been determined that the application performed positively affects students' reading comprehension status. It was determined that the students in the experimental group whose reading comprehension was applied were more successful than the students in the control group who did not practice, that they read in accordance with the reading rules and their reading comprehension skills improved. It was observed that the students who were afraid to read at the beginning of the application were more willing to read at the end of the application.
\end{abstract}

Structured Abstract: Introduction: Reading is the activity of making meaning from written symbols through collaboration of cognitive behaviors and psychomotor skills (Demirel, 1999, p. 133). Reading refers to the act of making meaning of sounds converted into letters (Schopenhauer, 2012, p. 9). Reading is the process of the delivery of visual stimuli to the brain and of classification and interpretation of those stimuli

\footnotetext{
* Dr. Öğr. Üyesi, Muş Alparslan Üniversitesi Eğitim Fakültesi Türkçe ve Sosyal Bilimler Eğitimi Bölümü Asst. Prof. Dr., Muş Alparslan University Faculty of Education Department of Turkish and Social Sciences Education ORCID 0000-0001-7213-1331

b.arici@alparslan.edu.tr

Bu araştırmanın uygulama bölümü 2016-2017 öğretim yılında Almanya/Nürnberg'de (Nürnberg Eğitim Ataşeliği Görev Bölgesinde) yapılmış olup 04/11/2016 tarih ve 12386980/200.264 sayılı olurla gerekli izin alınmıştır.

Cite as/ Atıf: Arıcı, B. (2020). Yurt dışında Türkçe ve Türk kültürü dersine katılan öğrencilerin Türkçe okuduğunu anlama başarıları, Turkish Studies - Education, 15(2), 635-650. https://dx.doi.org/10.29228/TurkishStudies.39818

Received/Geliş: 19 November/Kasım 2019

Checked by plagiarism software

Accepted/Kabul: 29 April/Nisan 2020

Published/Yayın: 30 April/Nisan 2020

Copyright (C INTAC LTD, Turkey

CC BY-NC 4.0
} 
by the relevant receptors in the brain. Reading is a physical process in terms of seeing and vocalizing and a mental process in terms of comprehension (Ö̈zbay, 2009, p. 9). Comprehension is the process of drawing conclusions and receiving messages from sound, words, narratives, texts and visual stimuli (events and facts) and understanding their main themes and obtaining information from them (Calp, 2005, p. 66). The objective of reading is comprehension and reading without comprehension is a waste of time (Gündüz \& Şimşek, 2011, p. 43).

\section{Literature Review}

Reading comprehension strategies (techniques) can be used to comprehend texts. Reading comprehension strategies are behavioral and mental activities performed before, during and after reading (Susar Kırmız1, 2008, p. 113). Güneş argues that some of the reading methods that can be used to help students develop reading comprehension skills are reviewing images, scanning and skimming lines (underlining them) and identifying hard-to-understand parts. He also states that reading comprehension can be promoted through such techniques as dividing a text into small units, taking notes, determining the subject and main theme of the text and summarizing it (2013, p. 220). Turkish education abroad is based on the "Turkish and Turkish Culture Course Curriculum for Turkish Children Abroad (Grades 1-10)" prepared by the Ministry of National Education (MNE). The curriculum consists of learning domains, learning outcomes, examples of activities, assessment and evaluation and explanations. The MNE $(2009$, p. 7) states that the Curriculum should consist of carefully selected texts about the Turkish culture written in correct, elegant and effective Turkish.

\section{Method}

At this study, it is used a pretest/posttest control group design to investigate the Turkish reading comprehension skills of students taking the Turkish and Turkish culture course (TTCC) abroad. The study population consisted of all TTCC students. The study sample consisted of 60 fourth-year students who in and around Nuremberg, Germany, those students are participated Turkish and Turkish Culture course. This study sample divided into two groups that are equal. Experimental (n: 30; 14 female and 16 male) and control (n: 30; 16 female and 14 male). Data were collected using a reading observation form (ROF) and aselfassessment form (SAF) prepared by the MNE and an exam form prepared by the researcher. ROF consists of 20 reading outcomes. SAF consists of ten questions about reading. The exam form consisted of a reading text and ten questions about reading comprehension. The Statistical Package for Social Sciences programme had used to analize for the data (SPSS v 23) at a significance level of 0.05. Frequencies and percentages were calculated for demographic characteristics. For data comparison pre-test and post-test were performed. The independent-sample $t$ test was used for analysis of SAF data. Prior to the training, participants were administered the exam form. After the reading training, the exam form was administered again as the posttest, and the results were compared and interpreted by the author.

\section{Findings and Discussion}

At this study investigated that the students' who attend Turkish and Turkish culture course, whose Turkish reading comprehension skills. Independent sample t test was used to compare the posttest scores of the experimental groups students and control groups students. The experimental group students scores means (81.00) had a significantly higher mean than the control group students (62.13). The independent sample $t$ test was used to compare the mean SAF scores of the experimental group and control group. The experimental group (78.03) had a significantly higher mean SAF score than the control group (59.47). The independent sample $t$ test was used to compare the mean ROF scores of the experimental and control groups. The experimental group students ROF scores mean and the control group students ROF scores mean had 78.28 and 55.06, respectively. Turkish teachers gave intensive reading comprehension training to the experimental group participants. The study's results showed that the reading training improved the experimental group participants' reading comprehension skills. After the reading training, the experimental group participants performed better and developed more reading comprehension skills than the control group participants. The training improved the experimental group participants' self-confidence as well. Before the training, they were reluctant to read, however, they were more eager to read after the training. The texts in the TTCC should, therefore, attract students' interest and help them develop reading skills and make reading more appealing. Moreover, activities and practices should be carried out to help students understand those texts better. The following practices are recommended to reduce the problems faced by students of Turkish origin who attend Turkish and Turkish culture lessons abroad, mostly of Turkish origin: 
- Students should have plenty of reading and comprehension exercises, and these studies should be enriched with multiple intelligence-supported activities (including educational games, etc.) that can attract the attention of each student.

- Also, the teacher and the parents had to be attention should be paid to the fact that the texts that will be presented to the students are texts that will improve their reading skills and make them enjoying reading.

- Worksheets that will include texts that comply with the levels specified in the European language portfolio and gradually increase in difficulty and texts containing elements from Turkey culture and the culture of the country where Turkish courses are held abroad should be developed and presented to students.

- Activities aiming at a basic understanding can be prepared (Göçer, 2018) and students' reading comprehension status can be developed with multiple choice questions, true-false, filling in spaces, $5 \mathrm{~N} 1 \mathrm{~K}$, ranking, comment, evaluation and summarizing questions (Ülper, 2019).

- Students should be provided with a reading culture (Sever, 2013).

- Students' interest in reading should be increased (Arıcı, 2018).

- Different reading techniques (Güneş, 2013) should be used before, during and after reading, and methods and techniques (Maden, 2018) that will ensure the continuation of reading activities outside the school.

Keywords: Turkish Education, Turkish and Turkish Culture Lesson, Reading, Reading Comprehension, Teaching Turkish Abroad.

Öz: Bu araştırma yurt dışında Türkçe ve Türk Kültürü dersine katılan öğrencilerin okuduğunu anlama beceri düzeylerini belirlemek amacıyla yapılmıştır. Araştırmanın çalışma grubunu Federal Almanya'nın Nürnberg şehri ve çevresinde öğrenim görerek burada Türkçe ve Türk Kültürü dersine katılan çoğunlukla da Türk kökenli olan 4. sınıf öğrencilerinden oluşan 30'ar kişilik iki grup (deney grubu 30, kontrol grubu 30) oluşturmaktadır. Basit seçkisiz örnekleme yöntemiyle çalışma grupları belirlenmiştir. Deney grubuna dört ay boyunca haftada iki saat okuduğunu anlama çalışmaları yaptırılmıştır. Kontrol grubuna ise bu çalışmalar yaptırılmamıştır. 2016-2017 öğretim yılının ikinci döneminde yapılan uygulamanın başında ve sonunda her iki gruba da aynı metinler okutturulmuş, gruplardaki öğrencilerden okuduklarına ilişkin soruları cevaplamaları istenerek öğrencilerin cevapları sınav formu ve MEB tarafından hazırlanan ölçmedeğerlendirme formu ile öz değerlendirme formu aracılığıyla değerlendirilmiştir. Araştırma öncesinde yapılan ön testte göre deney grubundaki öğrencilerin puan ortalaması 61,80 ; kontrol grubunda bulunan öğrencilerin puan ortalaması ise 61,60 olup gruplar arasında puan ortalaması yönünden önemli bir fark bulunamamıştır. Derslere katılan deney grubundaki öğrencilerin uygulama sonrasında yapılan sınavın ortalama puanları 81,00 kontrol grubunda bulunan öğrencilerin sınav puanlarının ortalaması ise 62,13 olarak tespit edilmiştir. Bu sonuçlara göre yapılan uygulamanın öğrencilerin okuduğunu anlama durumlarını olumlu yönde etkilediği tespit edilmiştir. Okuma-anlama uygulaması yapılan deney grubundaki öğrencilerin, uygulama yapılmayan kontrol grubundaki öğrencilerden daha başarılı oldukları, okuma kurallarına uygun olarak okudukları ve okuduğunu anlama becerilerinin geliştiği tespit edilmiştir. Uygulama başlangıcında okumaktan çekinen öğrencilerin uygulama sonunda okumaya daha istekli oldukları gözlenmiştir.

Anahtar Kelimeler: Türkçe Eğitimi, Türkçe ve Türk Kültürü Dersi, Okuma, Okuma-Anlama, Yurt Dişında Türkçe Öğretimi.

\section{Giriş}

Beyin insan vücudunun yönetim merkezidir ve bu merkez sinir sistemi aracıllğıyla bütün vücudu yönetmektedir. Beynin cerebrum (asıl beyin), beyin sap1 ve beyincik adlı üç bölümden oluştuğunu belirten Braverman, cerebrumun birbirine eşit iki yarımküreye ayrıldığını ve bu yarımkürelerinde loblardan oluştuğunu ifade etmektedir (Braverman, 2012, 29). Beynin arka tarafinda yer alan oksipital lobun görsel algılardan sorumlu olduğunu belirten Aamodt ve Wang, kulakların hemen üzerindeki temporal lobun (şakak lobu) işitme ve işitileni anlamlandırma, 
öğrenme, bellek ve duygusal tepkilerden sorumlu olduğunu ifade etmektedirler $(2011,54)$. Onlara göre beynin üst ve yan bölümlerini kapsayan paryetal (yan) lob da dokunma ve diğer duyulardan gelen uyarıları bir araya getirerek dikkatin hangi tarafa verileceğini sağlamaktadır. Önde yer alan frontal (ön lob/alın lobu) lob ise hareketle ilgili komutları verip konuşmayı üreten alanı barındırmakta ve ortama uygun davranışların seçilmesinden sorumludur. Beyindeki bu bölümler birbirleriyle ve organlarla bağlantılı çalışarak bireyin dış dünyayı algılamasını sağlarlar. Duyu merkezleri adı verilen bu bölümler aşağıdaki şekilde gösterilmiştir.

Şekil 1: Beyindeki Duyu Merkezleri

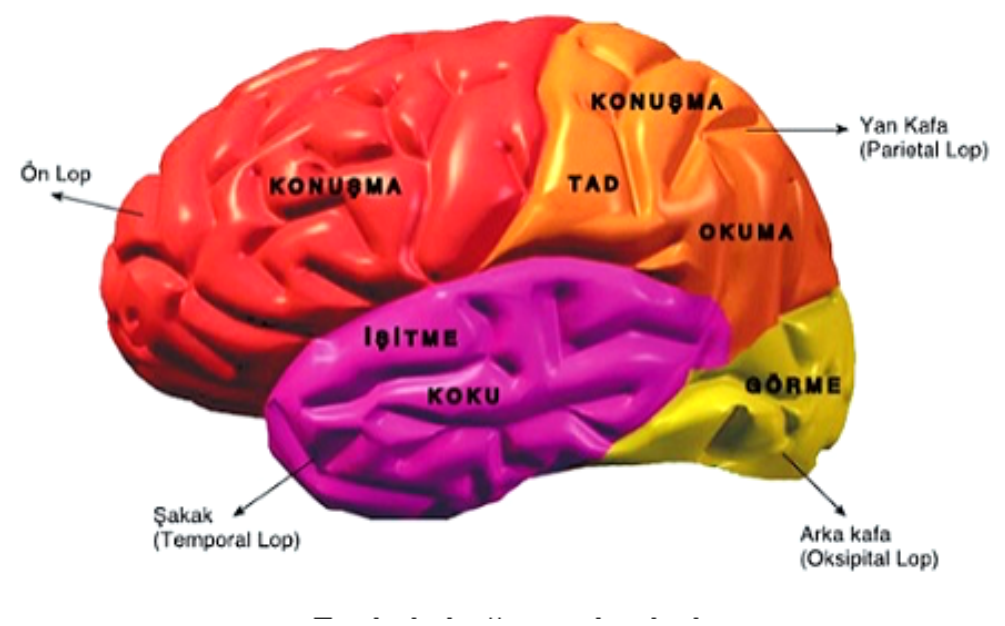

(Kaynak: https://webders.net/sinir-sistemi-ve-duyu-organlari-ders-20-363p2.html)

Yukarıdaki şekil incelendiğinde okuma eyleminin beyindeki parietal lob vasıtasıyla gerçekleştiği görülecektir. Bu lobun zarar görmesi matematik, okumayazma ve anlama sorunlarına neden olmaktadır.

\section{Okuma- Anlama}

Okuma, yazılı sembollerden anlam çıkarma (Demirel, 1999), harflere dökülmüş sesleri anlamlı sözcüklere dönüştürme (Schopenhauer, 2012), gözün görmesi ve beynin bunu anlamlandırma (Özbay, 2009) eylemi ve etkinliğidir. Başka bir deyişle okuma bireyin; "yazma sembollerinden harfleri ve kelimeleri tanıyp bu sembolleri sesli veya sessiz şekilde ifade etmesi”dir (Kayabaşı, Yılmaz ve Doyumğaç, 2016, 327). Okuma bazı sembollerin sesli veya sessiz bir şekilde ifade edilmesi olarak tanımlansa da temelde okuma, anlamlandırma ve anlam çıkarma sürecidir (Kıymaz ve Doyumğaç, 2019). Bu sürecin hatasız ve başarılı bir şekilde tamamlanabilmesi de ancak okumanın doğru bir biçimde öğrenilmesine ve uygulanmasına bağlıdır. Okuma eyleminin gözün bir noktaya odaklanıp diğer noktaya sıçrayarak gerçekleştiğini belirten Karatay $(2014,16)$, gözlerin kelimeleri tanıyarak beyne sinyal gönderdiğini ve bu sinyallerin de beyinde anlamlandırılmasıyla okuma eyleminin tamamladığıı ifade etmektedir. Okumayı öğrenmeye başlayan bir öğrencinin okuma esnasında yavaş yavaş söylenenden söylenmeyeni tahmin etmeye başladığını belirten Ferah $(2005,26)$, öğrencinin hatalarla beraber doğru tahmine ulaştığını, okuduklarında birlik-başkalık, benzerlik-zıtlık, aynılık-ayrılık arasındaki bağlantıları kurarak okumasını sağlam bir temele oturttuğunu ifade etmektedir. Okuma becerisinin kazandırılması için öğrencilere ders içerisinde ön okuma, okuma esnasında ve okuma sonrasında alıştırmalar yapmak gerektiğini belirten Arıcı $(2018,20)$, okuma öncesi yapılan araştırmaların öğrencilerin ön bilgilerini etkinleştirerek harekete geçirip öğrencilerin metinleri anlama becerilerini de geliştirdiğini ifade etmektedir. Öğrencilerin öyküleyici metinler aracıllı̆ıyla daha akıcı 
okudukları (Armut ve Türkyılmaz, 2017) bilinmektedir. Okuma becerisi geliştirilebilir ancak okuma becerisinin geliştirilmesinin yanında anlama becerisinin de geliştirilmesi gerekmektedir. Okumayı öğrenme ilkokul birinci sınıfta gerçekleşirken okuma becerisinin geliştirilmesi uzun yılar sürmektedir (Güneş, 2013, 140). Okuma öğretiminin bireylerin dil becerileri, iletişim becerileri, öğrenme ve anlama becerileri, zihinsel becerileri, sosyal becerilerinin yanında ve zihinsel bağımsızlık becerilerini de geliştirmeyi amaçladığını belirten Güneş $(2013,143)$, okumanın okuma tekniklerinin kullanılmasıyla geliştirileceğini savunmaktadır. Aksi takdirde birinci sınıfta okumayı öğrenen ama okuduğunu anlamayan bireyler yetiștirilecektir. Unutulmamalıdır ki anlam kurmayla sonuçlanmayan okumalar, sadece seslendirmedir (Yılmaz, 2018, 81). Okuma becerisinin geliştirilmesi okuma alışkanlığının kazanılmış olmasına bağlıdır.

Öğrencilere okuma alışkanlığının kazandırılmasının birinci basamağı onları tanımak (Bamberger, 1990) ve onları ilgi alanlarına uygun metinlerle okumaya başlatmaktır. Sonraki aşama ise okulun ilerleyen sınıflarında onları motive ederek devam etmeyi gerektirmektedir. Okuma alışkanlığının kazanılması belirli bir süreci gerektirip (Özbay, 2011) öğrencilerin okuma alışkanlığı kazanmasında öğretmenlerin etkisi anne-babanın etkisinden daha fazladır (Arıcı, 2005) ayrıca öğrencilerin arkadaşlarının kitap okuma ile ilgili faaliyetlerinin de yok denecek kadar az (Taşkesenlioğlu, 2013) olup bu konuda öğretmenlere ve ilgili kurumlara daha çok görev düşmektedir. Öğrencilerin kitap okuma ilgi ve alışkanlıklarının geliştirilmesi onların sonraki okul dönemlerini de ekkileyeceğinden (Bamberger, 1990) öğrencilerin her şeyden önce kitap okumanın gerekliliğine ve yaşamlarına olacak katkılarına inanmaları sağlanırsa okuma alışkanlığı kalıcı olacaktır.

Anlama, duyulan sesler, sözler ve anlatımlar ile okunan materyallerden, görülen olay ve olgulardan bir sonuç çıkarıp mesaj alma; anlatılmak isteneni kavrama ve bilgi edinme sürecidir (Calp, 2005, 66). Okumanın hedefi anlamaktır ve anlamanın olmadığı bir okuma zaman kaybıdır (Gündüz ve Şimşek, 2011, 43). Okunan metnin anlaşılması için okuduğunu anlama stratejileri (teknikleri) kullanılabilir. Bunlar okuma öncesinde, okuma sirasında ve okuma sonrasinda gerçekleştirilen davranışsal ve zihinsel etkinlikler bütünüdür (Susar Kırmızı, 2008). Okuduğunu anlamanın sadece metinde geçen ve okuyan tarafindan anlamı bilinmeyen kelimeleri anlamlandırarak o kelimelerin sözlükteki anlamlarını bulma olmadığını belirten Karatay (2014, 11)'a göre anlamak okunan metni bütün yönleriyle kavramaktır Okunan metnin anlaşılması için okumadan önce, okuma sırasında ve okuma eyleminden sonra takip edilmesi gereken aşamalar bulunmaktadır. Okuma öncesinde göz gezdirme, amaç oluşturma, ön bilgilerden yararlanma ve tahmin yapma; okuma sirasında akıcı okuma, anlamayı kontrol etme ve yardımcı stratejileri kullanma basamakları olduğunu belirten Akyol (2019, 35), okuma sonrasında özetleme ve değerlendirme yapılabileceğini ifade etmektedir.

Öğrencilerin okuduğunu anlama becerilerinin geliştirilmesi için de görselleri inceleme, satılların üstünden geçme-altını çizme, anlaşılmayan yerleri belirleme gibi tekniklerin kullanılabileceğini belirten Güneş $(2013,220)$, metni küçük birimlere ayırma, not alma, metnin konusunu ve ana düşüncesini belirleyip metni özetleme gibi tekniklerin de anlamay1 kolaylaştıracağını ifade etmektedir. Öğrencilerin okunan metni anlayabilmesi için okunan metinle ilgili kısa bir konuşma yapılması ve anlaşılması güç kelimelerin anlamlarının açıklanması gerektiğini belirten Korkmaz (2008, 101), öğrencilerin metni önce kendileri okuyup daha sonra başkalarından dinlemelerini takiben okuduğunu anlama çalışmalarının yapılarak anlama durumunun kontrol edilmesi gerektiğini ifade etmektedir.

Yurt dişında Türkçe ve Türk Kültürü dersine katılan öğrencilerin okuduklarını anlamadıkları (Belet, 2009) veya anlamakta zorlandıkları (Yıldız, 2013) çeşitli araştırmacılar tarafindan ortaya konulmuştur. Ana dilinde ve yabancı dilde okuma süreçleri temelde benzer süreçler olarak algılansa da bu süreçler farklı şekillerde devam ederler. Çünkü ikinci dilde ya da yabancı dilde okuma ana dildeki okumadan daha karmaşıktır. Okuma becerisinin ve gelişiminin 
nasıl olduğunu açılama, hedef dilin özellikleri ve yazı sistemine göre değişkenlik göstermektedir (Hasırc1, 2016). Ayrıca Türkçeyi yabancı dil veya ikinci dil olarak öğretirken öğrencilerin bu öğrenmelerini alışkanlık (Arslan, 2011) haline getirip kullanmaları halinde daha kolay öğrenecekleri bilinen bir gerçektir. Çünkü dilin öğrenilmesi fazlaca uygulama yapılmasına bağlıdır. Bütün bunların yanı sıra yabancı dil olarak Türkçe öğrenenlerin okuduklarını metni anlamaları için düzeylere göre metin uyarlamak, metni sadeleştirmek, yeniden yazmak, üretmek ve özetlemek, önemlidir (Kıymaz ve Doyumğaç, 2019).

\section{Türkçe ve Türk Kültürü Dersleri}

Türkçe ve Türk Kültürü dersleri, yurt dışında çoğunlukla Türk ve Türk soylulara Türkçe öğretmek amaciyla verilen bir ders olup bu ders Türkiye'deki Türkçe öğretimi ve Yabancılara Türkçe Öğretimi derslerinden farklı (Arı ve Kayır, 2018) bir derstir. Bu ders ana dili Türkçe olan ancak bulundukları ülkenin dilinin baskın olduğu ve konuşulduğu yerlerde ana dil dersi olarak verilmektedir. Bu dersleri Milli Eğitim Bakanlığı tarafından görevlendirilen öğretmenler Türkçe ve Türk Kültürü Dersi Öğretim Programına (1, 2, 3, 4, 5, 6, 7, 8. Seviyeler) göre yürütmektedirler. Bu öğretim programında öğrencilerin; dinleme/izleme, konuşma, okuma ve yazma becerilerinin geliştirilip Türkçeyi kurallarına uygun bilinçli konuşup yazarak doğru ve özenli kullanmaları, duygu, düşünce ve hayal dünyalarını geliştirerek millî, manevi, ahlaki, tarihî, kültürel, sosyal değerlerimizi tanıyı severek benimseyip millî duygu ve düşüncelerinin kuvvetlendirilmesi amaçlanmıştır (MEB, 2018). Milli Eğitim Bakanlığı tarafından yurt dışında Türkçe öğretimi Avrupa ülkelerinin kendi okullarında Türkçe ve Türk kültürü derslerinde yapılmaktadır. Bu dersler yurt dışındaki okullarda çoğunlukla seçmeli ders niteliğinde olup bazı okullarda ise yabancı dil dersi niteliğinde verilmektedir.

Yurt dışında yaşayan ve Türkçe öğrenmek isteyen çocuklara Türkçe öğretmek amacıyla hazırlanan öğretim programında ise 4 . ve 5. seviyedeki okuma kazanımları aşağıdaki biçimde yer almaktadır (MEB, 2018, 9):

- Okuduğu metnin konusunu belirler.

- Yazıli yönergeleri takip eder.

- Noktalama işaretlerine dikkat ederek okur.

- Vurgu, tonlama ve telaffuza dikkat ederek okur.

- Okuduklarında geçen bilmediği kelimelerin anlamlarını bulur.

- Okuduklarında geçen söz varlığı unsurlarının anlamlarını bulur.

- Okuduklarında geçen kelimelerin eş anlamlılarını bulur.

- Okuduklarında geçen kelimelerin zıt anlamlılarını bulur.

- Okuduğu metni ana hatlariyla anlatır.

- Okuduğu metindeki gerçek ve hayalî ögeleri ayırt eder.

- Okuduklarında geçen eş sesli kelimelerin anlamlarını bulur.

- Metnin ana fikrini/ana duygusunu belirler.

- Okuduklarını özetler.

- Metinler arasında karşılaştırma yapar.

- Okudukları metinlerden çıkarım yapar.

- Metin türlerini ayırt eder.

- Okuma stratejilerini kullanır.

- Medya metinlerini değerlendirir

Yukarıdaki kazanımlara dikkat edildiğinde 4. ve 5. seviyedeki öğrencilerinin kurallara uygun bir biçimde okumaları ve okudukları metinleri anlamaları beklenmektedir. Ancak çeşitli araştırmacılar tarafindan yapılan araştırmalarda yurt dışında Türkçe ve Türk kültürü dersine katılan 
öğrencilerin okuduğunu anlama sorunlarının bulunduğu tespit edilmiştir. Yurt dişında Türkçe ve Türk Kültürü dersine katılan öğrencilerin doğru okuyamama ve kaynağa ulaşamama sorunları da bulunmaktadır. Çakır (2003), yetişkinlerin çok isteseler de çocuklarına sunabilecekleri, onların gokuma ihtiyaçlarını karşılayabilecekleri kaliteli çocuk kitaplarına ulaşamadıklarından, çocuk ve gençlerin kendi yaşlarına uygun okuma kitapları bulamayıp rastlantılar sonucunda ulaştıkları Türkçe kitaplarla yetindiklerini ya da Alman yaşıtlarının okudukları Almanca kitaplara yöneldiklerini ifade etmektedir Yurt dışında Türkçe öğretimiyle ilgili olarak Belet (2009), tarafindan yapılan bir araştırmaya katılan Türkçe ve Türk kültürü öğretmenleri Türkçe öğretimi için öğrencilere sunulan kaynakların, Türkçe ders saatlerinin ve buna bağlı olarak ders kitabı içeriklerinin yetersiz olduğundan; Türkçe öğretiminin sistemli olarak yapılmadığından bahsetmişlerdir. Yurt dışında Türkçe öğrenen çocuklar önce yaşadıkları ülkenin dilini öğrendikleri için Türkçe kitabında yer alan metinleri okuyup herhangi bir metni yazarken o dil ile Türkçenin cümle yapısındaki farkları hissedip bunun aşılamaz bir problem olduğunu düşünmektedirler (Demir, 2010). Yıldız $(2012,39)$, tarafından yapılan bir araştırmaya katılan öğrencilerin \% 78,8'i Türkçe derslerinde öğrencilere sunulan ve kitaplarda yer alan okuma parçalarının çok sıkıcı olduğunu ifade etmişlerdir. Bütün bunlara ek olarak Türkiye'de ve diğer ülkelerde Türkçe öğreten çok sayıda kurum ve kuruluş bulunduğunu belirten Alyılmaz (2018), bu kurumların Türkçe öğrettikleri hedef kitlenin durumu, Türkçeyi öğrenme amaçları ve ihtiyaçlarını dikkate almadıklarını ifade etmektedir. Yurt dışında Türkçe öğretmek için hazırlanan kitaplar yetersiz olsa bile bazı gayretli öğretmenlerin bu olumsuzlukları ortadan kaldırmaya yönelik bireysel çalışmaları bulunmaktadır. Bu çalışmadan önce de araştırmacı tarafından öğrencilerin okuduğunu anlama durumları incelenmiş ve onların bu sorunlarının ortadan kaldırılması için araştırma yapılmıştır.

$\mathrm{Bu}$ araştırmada genel amaca ulaşmak için aşağıda yer alan soruların yanıtı bulunmaya çalışılmıştır:

1- Yurt dişında Türkçe ve Türk kültürü dersine gönüllü olarak katılan öğrencilerin okuduğunu anlama durumları nasıldır?

2- Yurt dışında Türkçe ve Türk kültürü dersine gönüllü olarak katılan öğrenciler kendi okuma-anlama durumlarını nasıl değerlendirmektedirler?

3- Yurt dışında Türkçe ve Türk kültürü dersine gönüllü olarak katılan öğrencilerin okuduğunu anlama sorunları çeşitli uygulamalarla ortadan kaldırılabilir ya da azaltılabilir mi?

\section{Yöntem}

$\mathrm{Bu}$ araştırmanın uygulama bölümü 2016-2017 öğretim y1lında Almanya/Nürnberg'de (Nürnberg Eğitim Ataşeliği Görev Bölgesinde) yapılmış olup 04/11/2016 tarih ve 12386980/200.264 sayılı olurla gerekli izin alınmıştır.

\section{Araştırma Modeli}

$\mathrm{Bu}$ araştırma okuma-anlama etkinliklerinin yurt dışında Türkçe ve Türk kültürü dersine katılan öğrencilerin Türkçe öğrenme başarılarına etkisini tespit etmek amacıyla yarı deneysel desende, ön test-son test kontrol gruplu modelde yapılmıştır. Araştırmada nicel veri analiz yöntemleri kulllanılmıştır. Araştırma yapılırken önbilgi anketi olarak Türkçe ve Türk kültürü dersi sınav formu uygulanmıştır. $\mathrm{Bu}$ modelde ön testler bulunup grupların deney öncesine ilişkin benzerlik dereceleri bilinip (Karasar, 2011) uygulama bu duruma göre düzenlenmektedir. Bu modelde iki gruba da deney öncesi ve sonrasında ölçmeler yapılmaktadır.

\section{Örneklem/Çalışma Grubu}

$\mathrm{Bu}$ araştırmanın çalışma grubunu Federal Almanya Bayern eyaleti Nürnberg şehri ve çevresinde Türkçe ve Türk kültürü dersine katılan dördüncü sınıf öğrencileri oluşturmaktadır. Araştırmaya deney grubunda on dört kız, on altı erkek öğrenci; kontrol grubunda ise on altı kız, on 
dört erkek öğrenci katılmıştır. Araştırmada deney grubu ve kontrol grubu seçilirken öğrencilere önbilgi anketi uygulanmış ve test sonuçları $\mathrm{P}<0.05$ düzeyinde anlamsız bulunmuştur.

Tablo 1: Araştırmaya Katılan Öğrencilerin Demografik Bilgileri

\begin{tabular}{cccc}
\hline Gruplar & Kiz & Erkek & \% \\
\hline Deney G. & 14 & 16 & 50 \\
\hline Kontrol G. & 16 & 14 & 50 \\
\hline
\end{tabular}

\section{Veri Toplama Araçları}

Araştırmada veri toplamak için MEB tarafından hazırlanıp kitaplara konulan okuma gözlem formu ile öz değerlendirme formu ve araştırmacı tarafından hazırlanan sınav formu (önbilgi anketi) kullanılmıştır. Okuma gözlem formu, yirmi okuma kazanımından; öz değerlendirme formu okumayla ilgili on sorudan; sınav formu bir okuma metni ile okuduğunu anlamaya ilişkin on sorudan oluşmaktadır.

\section{Önbilgi Anketi}

Önbilgi anketinin amacı öğrencilerin Türkçe okuma-anlama düzeylerini ölçmektir. $\mathrm{Bu}$ amaçla 20 çok amaçlı sorudan oluşan anket araştırmacı tarafindan hazırlanmıştır. Anket hazırlanırken Türkçe ve Türk Kültürü öğretim programı esas alınmıştır. Ayrıca önbilgi anketi hazırlanırken Türkçe eğitimi alanındaki öğretim üyelerinin görüşüne başvurulmuş ve onların da önerileri doğrultusunda ankete son hali verilmiştir. Anketin güvenirliği .84 bulunmuş, önbilgi anketi deney grubu ve kontrol gurubuna ön test olarak uygulanmıştır.

\section{Sinav Formu}

Sınav formunun amacı deney ve kontrol grubu öğrencilerinin Türkçe okuma-anlama durumlarını ölçmektir. Bu amaçla 10 çoktan seçmeli sorudan oluşan sınav formu hazırlanmıştır. Sınav formu hazırlanırken konuyu ölçen kazanımlara dikkat edilerek maddeler hazırlanmıştır. Türkçe ve Türk Kültürü öğretim programındaki kazanımlarına uygun olarak hazırlanan soruların görünüş geçerliği için uzman görüşüne başvurulmuştur. Testin ortalama güçlüğü .58 ve ortalama ayırt edicilik endeksi de .51 olarak bulunmuştur. Türkçe ve Türk kültürü dersi sınav formu bu araştırmaya katılan deney grubundaki öğrenciler ile kontrol grubunda yer alan öğrencilere ön test/son test halinde uygulanıp sonuçlar analiz edilmiştir.

\section{Verilerin Analizi}

Araştırmada formlarla edinilen veriler kodlanıp SPSS 23.00 istatistik paket programıla analiz edilmiştir. Katılımcıların demografik özelliklerine yönelik frekans ve yüzdeler hesaplanmıştır. Deney grubu ve kontrol grubu olarak ayrılan öğrencilerden elde edilen verilerin karşılaştırılması için ön test - son test ile öz değerlendirme formunun analizi bağımsız örneklem t testi (Independent-sample $t$ test) ile yapılmıştır. Uygulamaya başlamadan önce deney grubunda yer ve kontrol grubunda yer alan öğrencilere önbilgi sınav formu uygulanmıştır. Uygulama sonrasında ise deney ve kontrol grubundaki öğrencilere bu sınav formu son test olarak tekrar uygulanmış ve sonuçlar karşılaştırılarak yorum yapılmıştır.

\section{Bulgular}

\section{Yurt Dışında Türkçe ve Türk Kültürü Dersine Katılan Öğrencilerin Okuma-Anlama Durumları Ön Test Sonuçlarına İlişkin Bulgular}

Deney grubu ve kontrol grubunda bulunan öğrencilerin arasında uygulama öncesi bilgiler bakımından istatistikî olarak anlamlı bir farkın olup olmadığının belirlenmesi amacıyla deney ve kontrol grubundaki öğrencilere önbilgi sınav formu ve öz değerlendirme formu uygulanmıştır.

Deney grubu ve kontrol grubunda bulunan öğrencilerin ilgili sınav formundan aldıkları 
puanların aritmetik ortalamaları arasındaki farklar bağımsız örneklem $\mathrm{t}$ testi ile analiz edilmiş olup ön-test sonuçlarına ait karşılaştırmalar Tablo 2'de gösterilmiştir.

Tablo 2: Sınav Formu Ön-Test Puanları Bağımsız Örneklem T Testi Sonuçları

\begin{tabular}{ccccc}
\hline Gruplar & $\mathbf{N}$ & $\overline{\mathbf{X}}$ & $\mathbf{s d}$ & Std. Error Mean \\
\hline Deney G. & 30 & 61,80 & 6,478 & 1,183 \\
\hline Kontrol G. & 30 & 61,60 & 5,823 & 1,063 \\
\hline
\end{tabular}

Tablo 2'ye göre yurt dişında Türkçe ve Türk kültürü dersine katılan deney ve kontrol grubundaki öğrencilerin uygulama öncesinde yapılan sınav sonucunda ortalama puanlarının birbirine yakın olduğu ve puanlarının arasında anlamlı bir fark bulunmadığ 1 (deney grubu 61,80, kontrol grubu 61,60) tespit edilmiștir.

\section{Yurt Dışında Türkçe ve Türk Kültürü Dersine Katılan Öğrenciler Kendi Okuma- Anlama Durumları Ön Test Sonuçlarına İlişkin Bulgular}

Deney grubu ve kontrol grubunda bulunan öğrencilerin ilgili öz değerlendirme formuna verdikleri cevapların ortalamaları arasındaki farklar bağımsız örneklem $t$ testi ile analiz edilmiş olup ön-test sonuçlarına ilişkin karşılaştırmalar Tablo 3 'te gösterilmiştir.

Tablo 3: Öz Değerlendirme Formu Ön-Test Puanları Bağımsız Örneklem T Testi Sonuçları

\begin{tabular}{ccccc}
\hline Gruplar & $\mathbf{N}$ & $\overline{\mathbf{X}}$ & sd & Std. Error Mean \\
\hline Deney G. & 30 & 54,20 & 1,243 &, 227 \\
\hline Kontrol G. & 30 & 54,43 & 1,194 &, 218 \\
\hline
\end{tabular}

Tablo 3'e göre yurt dışında Türkçe ve Türk kültürü dersine katılan deney ve kontrol grubundaki öğrencilerin uygulama öncesinde kendilerine sunulan öz değerlendirme formuna verdikleri cevapların ortalama puanlarının birbirine yakın olduğu ve puanlarının arasında anlamlı bir fark bulunmadığı (deney grubu 54,20, kontrol grubu 54,43) tespit edilmiştir.

Deney grubu ve kontrol grubunda bulunan öğrencilerin öğretmenleri tarafindan doldurulan gözlem puanlarının ortalamaları arasındaki farklar bağımsız örneklem $t$ testi ile analiz edilmiş olup ön-test sonuçlarına ilişkin karşılaştırmalar Tablo 4 'te gösterilmiştir.

Tablo 4: Öğretmenin Okuma Değerlendirme Formu Ön-Test Puanlarının Bağımsız Örneklem T Testi Sonuçları

\begin{tabular}{ccccc}
\hline Gruplar & $\mathbf{N}$ & $\overline{\mathbf{X}}$ & sd & Std. Error Mean \\
\hline Deney G. & 30 & 54,33 & 1,269 &, 232 \\
\hline Kontrol G. & 30 & 54,30 & 1,179 &, 215 \\
\hline
\end{tabular}

Tablo 4'e göre yurt dışında Türkçe ve Türk kültürü dersine katılan deney ve kontrol grubundaki öğrencilerin uygulama öncesinde kendilerine sunulan öz değerlendirme formuna verdikleri cevapların ortalama puanlarının birbirine yakın olduğu ve puanlarının arasında anlamlı bir fark bulunmadığ (deney grubu 54,33, kontrol grubu 54,30) tespit edilmiştir.

\section{Uygulama Süreci}

Deney grubuna dört ay boyunca haftada iki saat olmak üzere toplam otuz iki saat okuduğunu anlama çalışmaları yaptırılmıştır. Bu çalışmalarda dünya ve Türk edebiyatının seçkin örneklerine yer verilmiş, aşağıdaki takvime göre uygulama yapılmış olup örnek bir uygulama metni ekler bölümünde verilmiştir. 
Tablo 5: Uygulama Takvimi

\begin{tabular}{|c|c|c|c|}
\hline $\begin{array}{l}\text { Uygulama } \\
\text { Tarihi }\end{array}$ & $\begin{array}{c}\text { Uygulamada Kullanılan } \\
\text { metin }\end{array}$ & İlgili Metnin Yazarı & Yapılan Etkinlikler \\
\hline $31 / 01 / 2017$ & & Değerlendirme Sınavı (öntest) & \\
\hline $07 / 02 / 2017$ & Ağustos Böceği ile Karınca & $\begin{array}{l}\text { La Fontaine } \\
\end{array}$ & \multirow{8}{*}{$\begin{array}{l}\text { Anlama soruları, } \\
\text { bulmacalar ve } \\
\text { çalışma } \\
\text { yapraklarındaki } \\
\text { etkinlikler }\end{array}$} \\
\hline $14 / 02 / 2017$ & Kurbağa Prens & Grimm Kardeşler & \\
\hline $21 / 02 / 2017$ & Aslan ve Fare & Ezop & \\
\hline $28 / 02 / 2017$ & Keloğlan ile Kırmızı Taş & Türk Masalları & \\
\hline $07 / 03 / 2017$ & Kedi ve Fare & Grimm Kardeşler & \\
\hline $14 / 03 / 2017$ & $\begin{array}{c}\text { Yıldız Kız ve Mavi } \\
\text { Çiçekler }\end{array}$ & Avusturya Masalı & \\
\hline $21 / 03 / 2017$ & İbiş ile Memiş & Türk Masalları & \\
\hline $28 / 03 / 2017$ & Padişah ile Hizmetçisi & Beydeba & \\
\hline $11 / 04 / 2017$ & Boğaç Han & Dede Korkut Hikâyeleri & \multirow{8}{*}{$\begin{array}{l}\text { Anlama soruları, } \\
\text { bulmacalar ve } \\
\text { çalışma } \\
\text { yapraklarındaki } \\
\text { etkinlikler }\end{array}$} \\
\hline $18 / 04 / 2017$ & Kırmızı Ayakkabılar & H. Cristian Andersen & \\
\hline $25 / 04 / 2017$ & Tavşanla Kaplumbağa & La Fontaine & \\
\hline $02 / 05 / 2017$ & Keloğlan ile Çilli Tavuk & Türk Masalları & \\
\hline $09 / 05 / 2017$ & Hansel ve Gretel & Grimm Kardeşler & \\
\hline $16 / 05 / 2017$ & Kırmızı Başlıklı Kız & Charles Perrault & \\
\hline $30 / 05 / 2017$ & Yeşil Kuş & Türk Masalları & \\
\hline $13 / 06 / 2017$ & Doğruluk & Türk Masalları & \\
\hline $20 / 06 / 2017$ & & Değerlendirme Sınavı (sontest) & \\
\hline
\end{tabular}

Yurt Dışında Türkçe ve Türk Kültürü Dersine Katılan Öğrencilerin OkumaAnlama Durumları Son Test Sonuçlarına İlişkin Bulgular

Deney grubu ve kontrol grubunda bulunan öğrencilerin ilgili sınav formundan aldıkları puanların aritmetik ortalamaları arasındaki farklar bağımsız örneklem $\mathrm{t}$ testi ile analiz edilmiş olup son-test sonuçlarına ilişkin karşılaştırmalar Tablo 6'da gösterilmiştir.

Tablo 6: Sınav Formu Son-Test Puanlarına ait Bağımsız Örneklem T Testi Sonuçları

\begin{tabular}{llccc}
\hline Gruplar & $\mathbf{N}$ & $\overline{\mathbf{X}}$ & sd & Std. Error Mean \\
\hline Deney G. & 30 & 81,00 & 5,079 &, 927 \\
\hline Kontrol G. & 30 & 62,13 & 5,667 & 1,035 \\
\hline
\end{tabular}

Tablo 6’ya göre yurt dışında Türkçe ve Türk kültürü dersine katılan deney grubundaki öğrencilerin uygulama sonrasında yapılan sınavın ortalama puanlarının 81,00 olduğu; kontrol grubundaki öğrencilerin sınav puanlarının ortalamasının 62,13 olduğu tespit edilmiştir. Buna göre deney grubu ve kontrol grubunda bulunan öğrencilerin sınav son-test puanlarının arasında deney grubunun lehine anlamlı bir fark bulunmaktadır.

Yurt Dışında Türkçe ve Türk Kültürü Dersine Katılan Öğrenciler Kendi OkumaAnlama Durumları Son Test Sonuçlarına İlişkin Bulgular

Deney grubu ve kontrol grubunda bulunan öğrencilerin ilgili öz değerlendirme formuna verdikleri cevapların ortalamaları arasındaki farklar bağımsız örneklem $t$ testi ile analiz edilmiş olup son-test sonuçlarına ilişkin karşılaştırmalar Tablo 7'de gösterilmiştir. 
Tablo 7: Öz Değerlendirme Formu Son-Test Puanlarına ait Bağımsız Örneklem T Testi Sonuçları

\begin{tabular}{lcccc}
\hline Gruplar & $\mathbf{N}$ & $\overline{\mathbf{X}}$ & sd & Std. Error Mean \\
\hline Deney G. & 30 & 78,03 & 2,684 &, 490 \\
\hline Kontrol G. & 30 & 59,47 & 3,170 &, 579 \\
\hline
\end{tabular}

Tablo 7'ye göre yurt dışında Türkçe ve Türk kültürü dersine katılan deney grubundaki öğrencilerin uygulama sonrasında kendilerine sunulan öz değerlendirme formuna verdikleri cevapların ortalama puanı 78,03; kontrol grubundaki öğrencilerin öz değerlendirme formu puan ortalamaları 59,47 olarak bulunmuştur. Buna göre deney grubu ve kontrol grubunda bulunan öğrencilerinin öz değerlendirme formu son-test puanlarının arasında deney grubunun lehine anlamlı bir fark bulunmaktadır.

Deney grubu ve kontrol grubunda bulunan öğrencilerin öğretmenleri tarafindan yapılan gözlemlere göre öğrencilerin puan ortalamaları arasındaki farklar bağımsız örneklem t testi ile analiz edilmiş olup son-test sonuçlarına ilişkin karşılaştırmalar Tablo 8'de gösterilmiştir.

Tablo 8: Öğretmenin Okuma Değerlendirme Formu Son-Test Puanlarına ait Bağımsız Örneklem T Testi Sonuçları

\begin{tabular}{lcccc}
\hline Gruplar & $\mathbf{N}$ & $\overline{\mathbf{X}}$ & sd & Std. Error Mean \\
\hline Deney G. & 30 & 78,28 & 9,269 & 1,721 \\
\hline Kontrol G. & 30 & 55,06 & 5,573 & 1,001 \\
\hline
\end{tabular}

Tablo 8'e göre yurt dişında Türkçe ve Türk kültürü dersine katılan deney grubundaki öğrencilerin öğretmenlerinin uygulama sonrasında öğrencileri gözlemleyerek doldurduğu değerlendirme formunun puan ortalaması 78,28; kontrol grubundaki öğrencilerin öğretmenlerinin öğrenci değerlendirme formlarının puan ortalaması ise 55,06 olarak bulunmuştur.

\section{Sonuç, Tartışma ve Öneriler}

Araştırmada elde edilen bulgulara göre yapılan uygulamanın öğrencilerin okuduğunu anlama durumlarını olumlu yönde etkilediği tespit edilmiştir. Türkçe öğretmenleri tarafindan okuduğunu anlama uygulamasının yapıldığı deney grubundaki öğrencilerin uygulama sonunda kontrol grubunda bulunan öğrencilerden daha başarılı oldukları; okuma ve okuduğunu anlama becerilerinin daha çok geliştiği tespit edilen bu araştırma aynı zamanda öğrencilerin kendilerine güvenmelerini de olumlu etkilemiştir.

Uygulama başlangıcında okumaktan çekinen öğrencilerin uygulama sonunda okumaya daha istekli oldukları gözlenmiştir. Dolayısıyla yurt dışında Türkçe öğretimi yapılırken öğrencilere sunulacak okuma metinlerinin ögrencilerin yaşadıkları ülkelerden bilgiler içermesi ya da bu ülkelerin edebiyatlarının seçkin örneklerinden olması onları metne duygusal anlamda da yaklaştıracak, onlara okumayı sevdirecek metinler olmasına dikkat edilmelidir. Ayrıca ilgili metinlerin ögrenciler tarafindan anlaşılmasını sağlayacak etkinlik ve uygulamalara yer verilmelidir. Zaten Türkçe ve Türk Kültürü Dersi Öğretim Programında (1, 2, 3, 4, 5, 6, 7, 8. Seviyeler) okuma becerisi ile öğrencilerin günlük hayatlarında her an karşılarına çıkan yazılı metinleri doğru ve akıcı bir biçimde, uygun yöntem ve teknikleri kullanarak okuyup değerlendirerek eleştirel bir bakış açıcısıyla yorumlayıp okumayı alışkanlık hâline getirmelerini sağlamak amaçlanmıştır (MEB, 2018).

Almanya'da Türkçe derslerine katılan öğrencilerin yaklaşı \% 80’i Türkçe derslerindeki okuma parçalarının çok sıkıcı olduğunu (Yıldız, 2012); yurt dışında Türkçe öğrenen öğrencilerin Türkçe dersini önemli bir ders olarak görmemeleri, sözcük dağarcıklarının yetersiz olması, okuma alışkanlı̆̆ kazanmamış olmaları (Belet Boyacı, 2015) önemli sorunlar olarak bilinmektedir. Ayrıca yurt dışında Türkçe öğreten öğretmenlerin 2. ve 3. sınıf düzeyine uygun metinlerin olduğu kitaplara 
ihtiyaç duyulması (Sönmez, 2018) yurt dışında Türkçe okuma becerisinin öğretiminde karşılaşılan temel sorunlardandir.

Okuma-anlama sorunu sadece yurt dışında Türkçeyi ana dil olarak öğretmeyi hedefleyen Türkçe ve Türk Kültürü derslerinde değil Türkçenin önce ana dil sonra ikinci dil ve daha sonra da yabancı dil olarak öğretildiği bütün derslerde aşılması gereken en önemli engeldir. Okumanın arka planındaki bilgi dağarcığı ve bu dağarcığın oranının fazlalığının okumayı geliştirdiğini belirten Chung, öğrencilerin okuma sorunlarının temelinde kelime hazinelerinin yetersizliği ve okuma ihtiyaçlarının olduğunu ifade etmektedir (2012). İyi bir okuduğunu anlama yeteneğinin iyi dinlemeyi sağladığını belirten Olatunji ise günümüzde bunun kişilerarası ve sosyal etkileşimde çok önemli olduğunu ifade etmektedir (2011).

Dolayısıyla önce okuma becerisi geliştirilmeli, ardından okuma-anlama becerisini geliştirecek çalışmalar yapılmalıdır. Yurt dışında Türkçe ve Türk kültürü dersine katılan, çoğunluğunu Türk ve Türk soyluların oluşturduğu öğrencilerin okuma anlamada karşılaştıkları sorunların azaltılması için aşağıdaki uygulamaların gerçekleştirilmesi önerilmektedir:

- Öğrencilere bolca okuma-anlama çalışması yaptırılmalı, bu çalışmalar her öğrencinin dikkatini çekebilecek (eğitsel oyun vb. içeren) çoklu zekâ destekli etkinliklerle zenginleştirilmelidir.

- Ayrıca öğrencilere sunulacak metinlerin onların okuma becerilerini geliştirecek ve onlara okumayı sevdirecek metinler olmasına dikkat edilmelidir.

- Diller İçin Avrupa Ortak Öneriler Çerçevesi'nde belirtilen seviyelere uygun ve aşamalı olarak zorluk derecesi artan metinler ile Türk kültüründen ve yurt dışında Türkçe derslerinin yapıldığg ülkenin kültüründen ögeleri içeren metinlerin yer verileceği çalışma yaprakları geliştirilerek öğrencilere sunulmalıdır.

- Temel bir anlamayı amaçlayan etkinlikler hazırlanıp (Göçer, 2018), öğrencilerin okuma anlama durumları çoktan seçmeli, doğru-yanlış, boşluk doldurma, $5 \mathrm{~N} \mathrm{1K}$, sıralama, yorum, değerlendirme ve özetleme soruları (Ülper, 2019) ile geliştirilmelidir.

- Öğrencilere okuma kültürü (Sever, 2013) kazandırılmalıdır.

- Öğrencilerin okumaya karşı ilgileri (Arıc1, 2018) artırılmalıdır.

- Okuma öncesinde, okuma sırasında ve okuma sonrasında farklı okuma teknikleri (Güneş, 2013) ile okul dışında da okuma çalışmalarının sürdürülmesini sağlayacak yöntem ve teknikler (Maden, 2018) kullanılmalıdır.

* Bu araştırmanın uygulama bölümü 2016-2017 öğretim yılında Almanya/Nürnberg'de (Nürnberg Eğitim Ataşeliği Görev Bölgesinde) yapılmış olup 04/11/2016 tarih ve 12386980/200.264 sayılı olurla gerekli izin alınmıştır.

\section{Kaynakça}

Aamodt, S., Wang: (2011). Beyninize hoş geldiniz. (Çev. B. Erkan), İstanbul: NTV.

Akyol, H. (2019). Programa uygun Türkçe öğretim yöntemleri. Ankara: Pegem. https://doi.org/10.14527/9786053640011

Alyılmaz, S. (2018). Türkçe öğretiminde hedef kitlenin / "öğrenen"in önemi. Uluslararası Türkçe Edebiyat Kültür Ë̆itim Dergisi, 7(4), 2452-2463. https://doi.org/10.7884/teke.4368

Arı, A., \& Kayır, G. (2018). Türkçe ve Türk Kültürü Dersi Etkinlik Uygulamaları. Konya: Eğitim Yayınevi. 
Arıc1, A. F. (2005). İlköğretim ikinci kademe öğrencilerinin okuma durumları (beceri-ilgialışkanlık-eğilim). Erzurum: Atatürk Üniversitesi, sosyal bilimler enstitüsü, Türkçe eğitimi ana bilim dalı yayınlanmamış doktora tezi. https://doi.org/10.14520/adyusbd.486916

Arıcı, A. F. (2018). Okuma eğitimi. Ankara: Pegem.

Armut, M., \& Türky1lmaz, M. (2018). Ortaokul öğrencilerinin okuma becerileri üzerine bir inceleme. Erzincan Üniversitesi Eğitim Fakültesi Dergisi,20(1), 217-236. https://doi.org/10.17556/erziefd.330587

Susar Kırmızı, Arslan, D., Doğan, B., Deliveli, K., F., Yaylı, D. \& Akkaya, N. (2008). Etkinliklerle Türkçe ögretimi (Görsel Okuma Görsel Sunu). Bursa: Ekin Basım Yayın Dağıtım.

Arslan, M. (2011). Yabancılara Türkçe öğretim kılavuzu: temel seviye. Ankara: Nobel Akademik Yayıncilik.

Bamberger, R. (1990). Okuma Alışkanlığını Geliştirme. Ankara: Kültür Bakanlı̆̆ı.

Belet, Ş. D. (2009). İki dilli Türk öğrencilerin ana dili Türkçeyi öğrenme durumlarına ilişkin öğrenci, veli ve öğretmen görüşleri (Fjell ilköğretim okulu örneği, Norveç). Selçuk Üniversitesi Sosyal Bilimler Enstitüsü Dergisi, (21), 71-85. https://doi.org/10.18069/fusbed.82121

Beydeba. (2005). Kelile ve Dimne. (Çev. N. Külekçi). İstanbul: Serhat.

Braverman, E. (2012)). Daha genç beyin daha dinç zihin. (Çev. Z. Yalçınkaya), İstanbul: Butik.

Calp, M. (2005). Özel öğretim alanı olarak Türkçe öğretimi. Konya: Eğitim Kitabevi.

Ho Van Chung, M. A. (2016). A Study of reading comprehension problems in English Encountered by First Year Students of Faculty of Vietnamese Studies at HNUE (Doctoral dissertation, MA Thesis. Hanoi National University of Education).

Çakır, M. (2003). Almanya'daki çok kültürlü ortamlarda Türkçenin anadili olarak kullanımı. Sosyal Bilimler Dergisi, 2002-2003, 39-58.

Demir, T. (2010). Yurt dişındaki Türk çocukları için Türkçe ve Türk kültürü dersi öğretim programı kapsamındaki Türkçe dersi kazanımlarının değerlendirilmesi. Gazi Üniversitesi Gazi Eğitim Fakültesi Dergisi, 30(3). https://doi.org/10.17860/mersinefd.282398

Demirel, Ö. (1999). Türkçe öğretimi. Ankara: MEB.

Ergin, M. (1971). Dede Korkut Kitabı. Ankara: MEB.

Ferah, A. (2005). Her yönüyle Türkçe ilkokuma-yazma. İstanbul: MEB.

Göçer, A. (2018). Türkçe öğrenme ve öğretim yaklaşımlart-Metin işleme süreçli-Mikro öğretim uygulama örnekli. Ankara: Pegem. https://doi.org/10.14527/9786052414200

Gündüz, O., \& Şimşek, T. (2011). Okuma Eğitimi. Ankara: Grafiker.

Güneş, F. (2007). Türkçe öğretimi ve zihinsel yapılandırma. Ankara: Nobel.

Güneş, F. (2013). Türkçe öğretimi yaklaşımlar ve modeller. Ankara: Pegem. https://doi.org/10.14527/9786053644927

Hasırcı, S. (2016). Yabancılara Türkçe öğretiminde okuma becerisinin yeri. (Ed. Yıldırım, F., \& Tüfekçioğlu, B.) (Yabancı dil olarak Türkçe öğretimi: Kuramlar-yöntemler-becerileruygulamalar. Ankara: Pegem Akademi. https://doi.org/10.14527/9786052415689.08

Karasar, N. (2014). Bilimsel araştırma yöntemi. Ankara: Nobel Yayınevi.

Karatay, H. (2014). Okuma eğitimi kuram ve uygulama. Ankara: Pegem. 
Kayabaşı, B., Yılmaz, M., Doyumğaç, İ. (2016). Mustafa Ruhi Şirin'in hikâyelerinin okunabilirlik açısından incelenmesi. Adıyaman Üniversitesi Ĕgitim Bilimleri Dergisi, 6(2), 323-343. https://doi.org/10.17984/adyuebd.306772

Kıymaz, M. S. ve Doyumğaç, İ. (2019). Türkçenin Yabancı Dil Olarak Öğretiminde Temel Kavramlar ve Kurumlar. (Ed.Mehmet Nuri Kardaş). Türkçenin Yabancı Dil Olarak Öğretimi (43-82). Ankara: Pegem Akademi. https://doi.org/10.14527/9786052415689.11

Korkmaz, B. (2008). Okuma eğitimi. A. Tazebay ve S. Çelenk (Editör). Türkçe Öğretimi: İlkeYöntem-Teknikler, 70-130, Ankara: Maya Akademi.

La Fontaine, J. (2000). Masallar (Çev. S. Eyüboğlu). İstanbul: Türkiye İş Bankası.

Maden, S. (2018). Okuma yöntem ve teknikleri. Sevim, O., ve Söylemez, Y. (Editörler). Okuma eğitimi, 233-257, Ankara: Nobel.

Milli Eğitim Bakanlığı (2018). Türkçe ve Türk kültürü dersi öğretim programı (1, 2, 3, 4, 5, 6, 7 ve 8. Seviyeler). Ankara: MEB. https://doi.org/10.17860/mersinefd.282398

Olatunji, O. (2011). Reading Comprehension and Summary Skills. English Language and Communication Skills for Tertiary Education, Ibadan: Joytal Educational Services, 203226.

Özbay, M. (2009). Türkçe özel ögretim yöntemleri II. Ankara: Öncü Kitap.

Özbay, M. (2011). Anlama teknikleri: I okuma Ĕ̈itimi. Ankara: Öncü Kitap.

Schopenhauer, A. (2012). Okumak, yazmak ve yaşamak üzerine. (Aydoğan, A., Çev.). İstanbul: Şule Yay.

Sever, S. (2013). Çocuk edebiyatı ve okuma kültürü. İzmir: Tudem Yayınları.

Sönmez, H. (2018). Fransa'da Türkçe eğitiminin ihtiyaçları üzerine bir durum incelemesi. Electronic Turkish Studies, 13(27).

https://doi.org/10.7827/turkishstudies.14284

Taşkesenlioğlu, L. (2013). Ortaöğretim öğrencilerinin okuma alışkanlıkları üzerine bir inceleme. Karadeniz Sosyal Bilimler Dergisi, 5(9). https://doi.org/10.12780/uusbd61

Tezel, N. (2011). Türk masalları. İstanbul: Bilge kültür sanat.

Ülper, H. (2019). Okuma ve anlamlandırma becerilerinin kazandırllması. Ankara: Nobel.

Yıldız, C. (2012). Yurt dışında yaşayan Türk çocuklarına Türkçe öğretimi (Almanya örneği). Yurtdışı Türkler ve Akraba Toplulukları Başkanlı̆̆ı: Ankara.

Yılmaz, M. (2018). Yeni gelişmeler ışı̆̆ında Türkçe öğretimi. Ankara: Pegem Akademi. https://doi.org/10.14527/9786053646723

Xenos, Verlag. (2018). 100 geschichten klassiker. Hamburg: Xenos.

Webders (03/03/2020). https://webders.net/sinir-sistemi-ve-duyu-organlari-ders-20-363p2.html 


\section{EK: UYGULAMA ÖRNEĞİ}

\section{KELOĞLAN ILE ÇiLLi} TAVUK

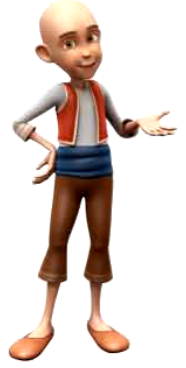

pek de güzelmiş. İnsanlarla ilgilenir, arkadaşlarına iyi davranır, hayvanları ve türkü söylemeyi çok sever fakat çalışmaktan pek hoşlanmazmış. Anası ona ne zaman bir iş buyursa bir bahane uydurur, anası kızınca da oraya buraya saklanırmış. Günlerden bir gün evinin kapısının önünde uyurken küçük bir çocuk yanına yaklaşmış:

- Hişt Keloğlan, Keleşoğlan, annesini üzen oğlaaannn, diye bağırmış. Keloğlan hemen arkasını dönmüş, uykusuna devam etmiş ve rüya görmeye başlamış. Rüyasında uzun bir yolda yürüyormuş, yürürken önce bir tavukla karşılaşıyormuş, tavuk;

- Ah Keloğlan bir bilsen başıma gelenleri, ne desem ne etsem bilmiyorum. Olup bitenleri önce sana anlatayım istersen demiş. Tilkilerin kendi kümesleri önünde nasıl gezdiklerini anlatmış durmuş. Keloğlan tam ona yardım etmek isterken, uyanmış. Uyanmış bir de ne görsün, onların evindeki çilli tavuk tam göbeğinin üstünde oturmuyor mu? Onu kanatlarından tutmuş hemen koşturup kümesin içine koymuş. Çilli tavuk neye uğradığını şaşırmış ama Keloğlan hâlâ rüyanın etkisinde olduğu için tilkinin çilli tavuğu götüreceğini düşünmüş.

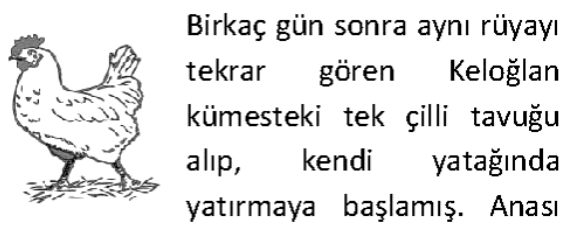

bu işe pek kızmış, ne işi varmış tavuğun yatakta, adam gibi kümese koysaymış ya. Keloğlan gözlerini ne zaman kapasa tilkinin çilli tavuğu kaçırdığını görüyormuş. En sonunda bakmış ki olmayacak, tilkiyi ziyaret etmeye karar vermiş.

Tilki bizim Keloğlan'ı görünce çok sevinmiş, onu yuvasına davet etmiş, bizimki tilkinin yuvasına girmiş bir de ne görsün, köydeki bütün kümeslerden çalınan tavuklar orada değil mi? Görmüş ama görmemezlikten gelmiş.

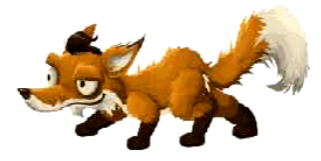

Tilki her zamanki gibi bir plan peşindeymiş ama Keloğlan'ın aklının ne kadar çabuk çalıştığını hesaba katmamış. Tilkinin yuvasında biraz oturan Keloğlan izin istemiş ama tilki ona izin verir mi hiç? Onun planı Keloğlan'ı da bir kafese kapatmakmış. Keloğlan önce bir hoplamış, duvarda asılı duran meşaleyi alıp kendi kel kafasına tutmuş, ona bakan tilkinin gözleri kamaşmış, Keloğlan bu sırada oradan uzaklaşmış. Tilki onu elinden kaçırdığı için mutsuzmuş, Keloğlan ise kahkahalar atacak kadar mutluymuş.

Daha sonra Keloğlan köylerinde tavuğu çalınan ne kadar köylü varsa onları toplayıp tilkinin evine getirmiş. Köylüler o kadar sinirlenmişler ki hırsız tilki korkudan evini barkını bırakıp kaçmış. Bir daha da onu oralarda gören olmamış. 
METİNLE İLGİLİ ÇALIŞMALAR

A- Așağıdaki kelimeleri bulmacada verilen boşluklara doğru bir biçimde yerleştiriniz.

$\begin{array}{ll}\text { KELOĞLAN } & \text { KAFES } \\ \text { CILLİ TAVUK } & \text { KÜMES } \\ \text { MEŞALE } & \text { TİKİ } \\ \text { PLAN } & \text { EV }\end{array}$

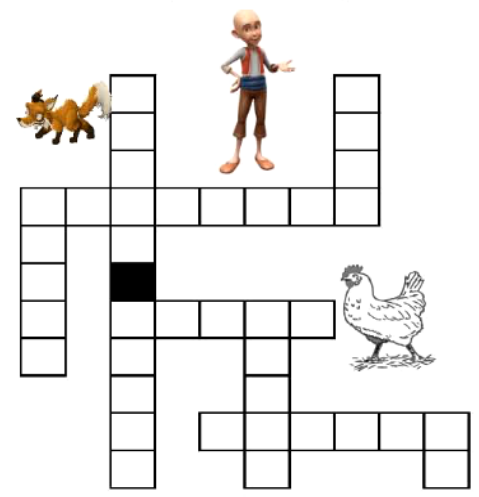

B- Aşağıdaki soruları cevaplayınız.

1- Annesi Keloğlan'a iş buyurunca Keloğlan ne yapıyormuş?

2- Cilli Tavuk Keloğlan'a neler anlatmış?

3- Tilkinin Keloğlan'la ilgili planı neymiş?

4- Keloğlan tilkinin elinden nasıl kurtulmus?
C- Öğretmeninizin dinlettiği Keloğlan'ın söylediği aşağıdaki türküdeki boşlukları tamamlayınız. Ben bir ............ Keloğlan'ım,
Eşeğimin yok ...................
Varım yoğum ..................
Hiç de sevmem ben ..............
Bir koca karı ............var.
Birkaç ........... bir de inek.
Her gün ............ kel kafama.

Evsiz kalmış bir kaç

Olmam ............ kul köle.

Halkın kulağı diliyim.

.

Sivri ...............biriyim.

Keloğlan'im budur

Haram ........... yoktur gözüm.

Garip ..............yiyene.

Elbet vardır bir çift

D- Siz Keloğlan'ın yerinde olsaydınız ne yapardınız?

E- Okuduğunuz metnin özetini aşağıdaki boşluğa yazınız.

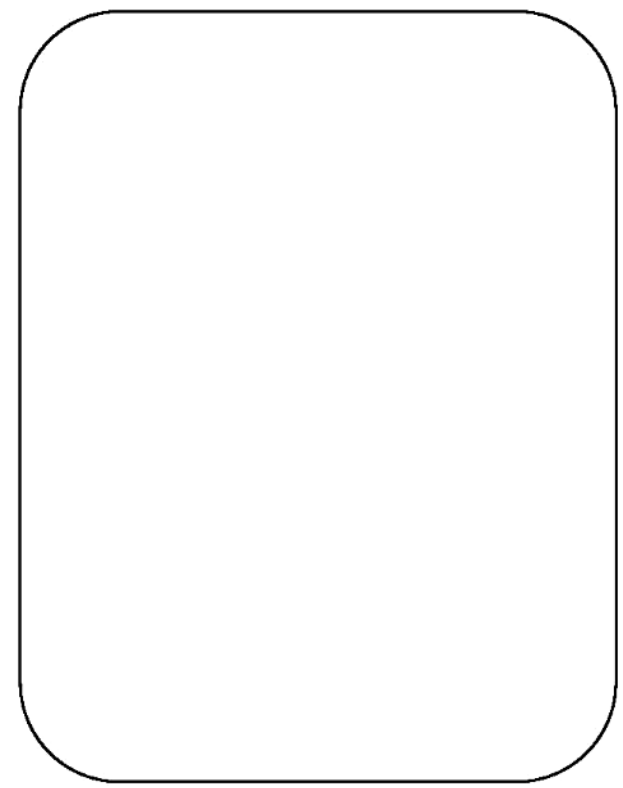

